\title{
STUDIES ON KINETICS AND ADSORPTION EQUILIBRIUM OF LEAD AND ZINC IONS FROM AQUEOUS SOLUTIONS ON SARKANDA GRASS LIGNIN
}

\author{
ELENA UNGUREANU, ${ }^{*}$ ALINA E. TROFIN, ${ }^{*}$ LUCIA C. TRINCĂ, \\ ADINA M. ARITON, ${ }^{* *}$ OVIDIU C. UNGUREANU, ${ }^{* * *}$ MARIA E. FORTUNĂ, ${ }^{* * * *}$ \\ DOINA C. JITĂREANU* ${ }^{*}$ and VALENTIN I. POPA*** \\ *"Ion Ionescu de la Brad" University of Life Sciences, Exact Sciences Department, \\ 3 Mihail Sadoveanu Alley, Iasi 700490, Romania \\ ${ }^{* *}$ Research Station for Cattle Breeding Dancu, 9 Ungheni Road, Iasi 707252, Romania \\ *** "Vasile Goldis" Western University of Arad, Department of Biology and Life Sciences, \\ 94 The Boulevard of the Revolution, Arad 310025, Romania \\ ***** "Petru Poni” Institute of Macromolecular Chemistry, 41A Grigore Ghica Voda Alley, \\ Iasi 700487, Romania \\ ****** “Gheorghe Asachi” Technical University of Iasi, Department of Natural and Synthetic Polymers, 73, \\ Prof. dr. docent Dimitrie Mangeron Alley, Iasi 700050, Romania \\ $\square$ Corresponding author: M. E. Fortună, fortuna.maria@icmpp.ro
}

Received June 10, 2021

In this study, the adsorption of $\mathrm{Pb}^{2+}$ and $\mathrm{Zn}^{2+}$ ions from aqueous solutions onto lignin obtained from unmodified Sarkanda grass was analyzed. To ensure optimal process conditions, the retention of lead and zinc ions was tested at different experimental parameters $(\mathrm{pH}$ of the initial solution and adsorbent, the dose of adsorbent, the concentration of aqueous solutions and contact time). The experimental results have been interpreted using the classic Langmuir and Freundlich isotherm models, as well as two kinetic models (the Lagergren pseudo-first order and the Ho and McKay pseudo-second order models). Based on the analysis of the experimental data, it has been concluded that unmodified Sarkanda grass lignin can be recommended as an efficient alternative, considering its practical applicability, in the retention of $\mathrm{Pb}^{2+}$ and $\mathrm{Zn}^{2+}$ ions from aqueous solutions, both in terms of the amount of adsorbate and pollutant species retained, as well as in terms of adsorption time.

Keywords: Sarkanda grass lignin, lead ions, zinc ions, adsorption, equilibrium, kinetics

\section{INTRODUCTION}

The compounds of renewable vegetable resources, such as lignin, can be considered as a strategic resource that can provide viable products, qualitatively and quantitatively, to sectors dependent on external factors (fuel, chemicals, electricity), also offering numerous advantages for the sustainable development of society. ${ }^{1}$

The literature on the reduction of environmental pollution has shown that a number of materials, which have a porous structure and a relatively large number of superficial functional groups can be used effectively to remove some pollutants from aqueous solutions. ${ }^{2}$ Due to the large adsorption capacity conferred by its structural characteristics and its extended specific surface, activated coal is considered a universal adsorbent, used worldwide for a variety of applications. ${ }^{2}$ Even though the removal of heavy metals can be successfully achieved by adsorption onto activated charcoal, this procedure is expensive and cannot be applied on an industrial scale. For this reason, it is advisable to find adsorbents that are available in large quantities and inexpensive.

The use of lignin as an adsorbent to remove pollutants, such as metal ions, from industrial wastewater can be considered a viable alternative,

Cellulose Chem. Technol., 55 (7-8), 939-948(2021) 
which can be a solution both to the problem of its complex recovery in the context of the diversification of raw materials and energy sources, and for reducing the content of pollutants in industrial wastewater. ${ }^{1}$ Statistical data concerning the depletion of wood resources have increased the interest in using non-wood products, for example, agricultural residues. ${ }^{3,4}$ Moreover, there is literature evidence of the quantitative retention of metal ions on lignin. ${ }^{5}$

The presence in its structure of numerous functional groups capable of forming chemical bonds with metal ions gives lignin a cationexchange capacity and provides it with the potential to be used as an adsorbent for the removal of heavy metal ions from wastewater. ${ }^{6}$

The adsorbability of heavy metal ions differs significantly depending on the type of lignin used as an adsorbent. For example, lignin extracted from black liquor, a by-product of the pulp and paper industry, has been demonstrated to have high adsorption capacities for $\mathrm{Pb}$ (II) and $\mathrm{Zn}$ (II), while the maximum adsorption capacity for $\mathrm{Pb}$ (II) and $\mathrm{Cd}(\mathrm{II})$ have been reported for beech wood and poplar wood lignin. ${ }^{7}$

Currently, the mechanisms involved in the adsorption of metal ions onto lignin are still under debate. Some studies have concluded that the ion exchange mechanisms ${ }^{8}$ may be responsible for the adsorption of metal ions onto lignin, while others suggested that the retention of metal ions on lignin by adsorption is the result of combining several mechanisms, such as ion exchange, adsorption and complexation. ${ }^{9-12}$

In general, the process of adsorption is influenced by $\mathrm{pH}$, the dose and nature of the adsorbent, the initial concentration of metal ions and contact time. ${ }^{10,13}$ An overview of the reported studies has revealed that most adsorbent materials in the "low-cost" category, to which lignin belongs as well, behave as effective adsorbents in a narrow $\mathrm{pH}$ range, weakly acidic to neutral: 4.0-
6.5. ${ }^{14}$ This is explained by the fact that the $\mathrm{pH}$ of the initial solution influences not only the speciation and solubility of polluting species (metallic ions), but also the degree of dissociation of functional groups on the surface of the adsorbent, considered as adsorption sites. ${ }^{15}$

The study of adsorption equilibrium is very important to determine the retention capacity of the adsorbent and establish the basic physicochemical parameters of the adsorption process. The Langmuir and Freundlich models are most commonly used for establishing the equilibrium conditions in adsorption processes and are considered classic models of adsorption isotherms. ${ }^{16}$ The kinetics of the adsorption process depends both on the retention process itself and on the diffusion stages that lead to the transfer of ions from the solution to the active sites on the surface of the adsorbent. ${ }^{17}$ The most commonly used kinetic models applicable to the adsorption of pollutants from aqueous solutions are the pseudo-first order Lagergren kinetic model, the pseudo-second order Ho and McKay kinetic model, and the intra-particle diffusion model.

In this context, the present investigation aims at evaluating the retention, under static conditions, of $\mathrm{Pb}^{2+}$ and $\mathrm{Zn}^{2+}$ ions on a chemically unmodified Sarkanda grass lignin substrate.

\section{EXPERIMENTAL}

\section{Materials and methods}

Unmodified Sarkanda grass lignin (Sarkanda grass100SA-140), supplied by Granit Recherche Development S.A. Lausanne, Switzerland, was used as an adsorbent substrate. It was expected that, as happens in adsorption processes, in contact with the aqueous solutions of the two polluting species $\mathrm{Zn}^{2+}$ and $\mathrm{Pb}^{2+}$, recognized for their high toxic potential (Table 1), many of the functional groups present in the lignin structure will dissociate and interact with the metal ions.

Table 1

Properties of unmodified Sarkanda grass lignin ${ }^{18}$

\begin{tabular}{lc}
\hline Properties of substrate & $\begin{array}{c}\text { Unmodified Sarkanda } \\
\text { grass lignin }\end{array}$ \\
\hline Lignin insoluble in acids, \% & 87 \\
Lignin soluble in acids, \% & 2 \\
Nitrogen, \% & 1.2 \\
COOH, mmol/g & 3.3 \\
Aromatic $\mathrm{OH}, \mathrm{mmol} / \mathrm{g}$ & 1.7 \\
Ash, $\%$ & 2.2 \\
$\mathrm{~T}$ (softening), ${ }^{\circ} \mathrm{C}$ & 160 \\
\hline
\end{tabular}


The stock solutions of metal ions in a concentration of $0.001 \mathrm{mg} / \mathrm{L}$ were prepared by dissolving separately the salts of $\mathrm{PbSO}_{4}$ and $\mathrm{ZnSO}_{4}$ in distilled water. The working solutions were prepared by diluting with distilled water an exact volume measured from the stock solutions, and the concentrations of metal ions in aqueous solutions are shown in Table 2.

For each metal ion studied, an appropriate spectrophotometric analysis method was chosen to add to the selectivity and accuracy of the determinations. A VIS Spectrophotometer V1000 SN was used to investigate the spectrophotometric analysis.

\section{Spectrophotometric determination of $\mathrm{Pb}(\mathrm{II})$}

The concentration of $\mathrm{Pb}^{2+}$ ions in aqueous solutions resulting from phase separation was determined using a method based on the reaction between $\mathrm{Pb}$ (II) and RIP ions (4-(2-pyridilazo)-resorcinol), in a basic medium ( $\mathrm{pH} 10$, ammonia buffer), when a stable red-orange complex with maximum absorption at $530 \mathrm{~nm}$ is obtained.

\section{Spectrophotometric determination of $\mathrm{Zn}(\mathrm{II})$}

The concentration of $\mathrm{Zn}(\mathrm{II})$ was determined by using Xylenol orange, which forms a red complex with $\mathrm{Zn}^{2+}$ ions, that can be investigated spectrophotometrically, with maximum absorption at $570 \mathrm{~nm}$. The choice of Xylenol orange for the spectrophotometric determination of $\mathrm{Zn}$ (II) in the extraction system phases is justified by the fact that the reaction color occurs in aqueous solutions, and the method is characterized by high sensitivity and precision.

Quantitative determination of the metal ions obtained after filtration from the aqueous solutions was carried out by analysis of an exactly measured volume $(2 \mathrm{~mL})$ according to the experimental procedure, and the concentration value for each sample was calculated from the regression equation of the calibration curve.

\section{Adsorption experiments}

The choice of the initial concentrations of the metal ions, the $\mathrm{pH}$ of the initial solution, the doses of the adsorbent, the temperature and the contact times between the two phases were established after some experimental tests, which led to optimum values for efficient development of static adsorption. Since some studies in the literature have shown that temperature variation has a fairly small effect on the effectiveness of the adsorption process of metal ions onto lignin, the influence of this parameter has not been considered in experimental studies. ${ }^{10}$ Thus, experiments were performed at room temperature $\left(20 \pm 0.5^{\circ} \mathrm{C}\right)$, using 5 $\mathrm{g}$ lignin as an adsorption substrate/ $\mathrm{L}$ of an aqueous solution of the two metal ions. This quantity was chosen as having an acceptable number of adsorption sites available for ion retention, given that in the case of lignin, the literature emphasizes a limited number of active sites. $^{10}$

The $\mathrm{pH}$ of the initial solution was 6.0 , because, at a low $\mathrm{pH}$, the presence of excess protons can compete with lead and zinc ions for lignin binding sites, and the level of the metal ions at higher $\mathrm{pH}$ values is higher because of the dissociation of functional groups of lignin. On the other hand, at a $\mathrm{pH}$ above 6.2 , there is the possibility of precipitation of the two ions, which affects the effectiveness of adsorption. ${ }^{19}$

Amounts of $20 \mathrm{~mL}$ of lead sulphate and zinc sulphate solutions were added to the lignin substrate in different concentrations (Table 2). Subsequently, the samples were left to rest, for different times (30, 60 and 90 minutes), in order to achieve the state of equilibrium and to capture the optimal retention time of the solution, thus obtaining information on the mechanism of adsorption and being able to interpret the data from a kinetic point of view.

After each resting period, phase separations by filtration were performed in order to determine the concentration of polluting species, using spectrophotometric methods, due to their high selectivity and sensitivity, relatively short working time, simple apparatus and possibility to be used successfully for quantitative analysis of metal ions.

\section{Isotherm models}

The starting point in the modeling the adsorption equilibrium is to obtain experimentally adsorption isotherms, which are then analyzed using mathematical models.

The adsorption efficiency of $\mathrm{Pb}^{2+}$ and $\mathrm{Zn}^{2+}$ was evaluated by determining the amounts of metal ion retained per unit mass of the adsorbent (q, mg/g) with the help of Equation (1): ${ }^{19}$

$\mathrm{q}=\left(\mathrm{C}_{\mathrm{i}}-\mathrm{C}_{\mathrm{e}}\right) \mathrm{V} / \mathrm{m},(\mathrm{mg} / \mathrm{g})$

where $\mathrm{C}_{\mathrm{i}}-$ initial concentration $(\mathrm{mg} / \mathrm{mL}) ; \mathrm{C}_{\mathrm{e}}-$ equilibrium concentration $(\mathrm{mg} / \mathrm{L}) ; \mathrm{V}-$ volume of metal ion solution $(\mathrm{L}) ; \mathrm{m}$ - mass of adsorbent $(\mathrm{g})$.

Mathematical models have been used to shape the adsorption isotherms to clearly determine the adsorption mechanism. The Langmuir model describes monolayer adsorption onto homogeneous surfaces, while the Freundlich model considers that the adsorption process takes place on relatively nonhomogeneous surfaces. The choice of the most appropriate model to describe the experimental data was made on the basis of the correlation coefficients $\left(\mathrm{R}^{2}\right)$ obtained for the linear representation of each model.

The Langmuir isotherm is expressed using Equation (2): ${ }^{19}$

$\mathrm{q}_{\mathrm{e}}=\mathrm{q}_{\text {max }}\left(\mathrm{k}_{\mathrm{L}} \cdot \mathrm{c}_{\mathrm{e}} / 1+\mathrm{k}_{\mathrm{L}} \cdot \mathrm{c}_{\mathrm{e}}\right)$

where $\mathrm{K}_{\mathrm{L}}=$ Langmuir constant related to free energy adsorption $(\mathrm{L} / \mathrm{mg}) ; \mathrm{q}_{\max }=$ maximum amount of metal ion retained on the absorbent after complete saturation; 
$(\mathrm{mg} / \mathrm{g}) ; \mathrm{q}_{\mathrm{e}}=$ amount of metallic ions adsorbed per unit of weight of adsorbent $(\mathrm{mg} / \mathrm{g})$ at equilibrium; $\mathrm{c}_{\mathrm{e}}=$ equilibrium concentration $(\mathrm{mg} / \mathrm{L})$.

Freundlich isotherm uses the empirical relationship (3): ${ }^{19}$

$\mathrm{q}_{\mathrm{e}}=\mathrm{k}_{\mathrm{F}} \cdot \mathrm{c}_{\mathrm{e}}{ }^{1 / \mathrm{n}}$

where $\mathrm{k}_{\mathrm{F}}=$ Freundich constant, indicating adsorption capacity; $\mathrm{n}=$ constant characterizing the affinity of metal ions to sorbent; $\mathrm{q}_{\mathrm{e}}=$ the amount of metallic ions adsorbed per unit of weight of adsorbent $(\mathrm{mg} / \mathrm{g})$ at equilibrium; $c_{e}=$ concentration at equilibrium of metal ions in solution $(\mathrm{mg} / \mathrm{L})$.

\section{Kinetic models}

With the help of the kinetic models of Lagergren and Ho \& McKay, the kinetic parameters of the adsorption process of $\mathrm{Zn}$ (II) and $\mathrm{Pb}$ (II) ions onto lignin can be determined from the slopes and the orderly intercept of linear dependencies $\lg \left(\mathrm{q}_{\mathrm{e}}-\mathrm{q}_{\mathrm{t}}\right)$ and $\mathrm{t}$, respectively, $\mathrm{t} / \mathrm{q}_{\mathrm{t}}$ and $\mathrm{t}$.

The equation for the Lagergren model for adsorption in a liquid-solid system is shown as follows: ${ }^{20}$

$\lg \left(\mathrm{q}_{\mathrm{e}}-\mathrm{q}_{\mathrm{t}}\right)=\lg \mathrm{q}_{\mathrm{e}}-\left(\mathrm{k}_{1} / 2,303\right) \mathrm{t}$ (linear shape)

The equation of the Ho \& McKay model reflects the adsorption capacity of the solid phase and is expressed through the following relationship: ${ }^{20}$

$\mathrm{t} / \mathrm{q}_{\mathrm{t}}=\left(1 / \mathrm{k}_{2} \cdot \mathrm{q}_{\mathrm{e}}^{2}\right)+\mathrm{t} / \mathrm{q}_{\mathrm{e}}$ (linear shape)

where $\mathrm{k}_{1}, \mathrm{k}_{2}=$ constant adsorption rates for model 1 and 2 ; respectively; $\mathrm{q}_{\mathrm{e}}, \mathrm{q}_{\mathrm{t}}=$ adsorption capacity at equilibrium and at time $t$, respectively.

\section{RESULTS AND DISCUSSION}

Effects of experimental parameters on $\mathrm{Pb}$ (II) and $\mathrm{Zn}$ (II) removal by adsorption on lignin

Taking into account the nature of the functional groups present on the surface of lignin and its structural peculiarities, it follows the possibility of forming coordinative bonds, due to its good affinity with metal ions, such as $\mathrm{Pb}^{2+}$ and $\mathrm{Zn}^{2+}$.

During the optimization of the experimental conditions of $\mathrm{Pb}^{2+}$ and $\mathrm{Zn}^{2+}$ adsorption, it was aimed to use a lower dose of lignin, which is especially advantageous from an economic point of view. Literature data recommend a dose of lignocellulosic adsorbent in the range of 4-40 $\mathrm{g} / \mathrm{L} .{ }^{13}$ The experimental tests have established that, at $5 \mathrm{~g}$ lignin/L aqueous solution of metal ions, the most efficient retention of the pollutant species studied is recorded.

\section{Initial concentration of $\mathrm{Pb}^{2+}$ and $\mathrm{Zn}^{2+}$}

In order to obtain the most conclusive information about the adsorption efficiency, the quantity of $\mathrm{Pb}^{2+}$ and $\mathrm{Zn}^{2+}$ retained on the unit of mass of lignin $(\mathrm{q}, \mathrm{mg} / \mathrm{g}$ ) was calculated.

As expected, the increase in the initial concentration of metal ions and the contact time between the two phases causes an increase in the adsorption capacity of lignin until most functional groups of lignin are fully occupied. At this point, the diffusion to the unreacted functional groups (free), which are found inside lignin particles, will most likely be hampered.

\section{Initial solution $\mathrm{pH}$}

With the increase in the $\mathrm{pH}$ of the initial solution, there occurs the deprotonation of the functional carboxyl and hydroxyl groups on the surface of lignin, and they become negatively charged, binding $\mathrm{Pb}^{2+}$ and $\mathrm{Zn}^{2+}$ from the aqueous solution.

Table 2

Quantity of $\mathrm{Pb}^{2+}$ and $\mathrm{Zn}^{2+}$ retained per unit mass of lignin (q, mg/g)

\begin{tabular}{|c|c|c|c|c|c|c|c|}
\hline \multirow{3}{*}{$\begin{array}{l}\mathrm{C}_{\mathrm{Pb} 2+} \\
(\mathrm{mg} / \mathrm{L})\end{array}$} & \multirow{2}{*}{\multicolumn{3}{|c|}{$\frac{\mathrm{q}_{\mathrm{Pb}}{ }^{2+}(\mathrm{mg} / \mathrm{g})}{\text { Time (minutes) }}$}} & \multirow{3}{*}{$\begin{array}{l}\mathrm{C}_{\mathrm{Zn} 2+} \\
(\mathrm{mg} / \mathrm{L})\end{array}$} & \multicolumn{3}{|c|}{$\mathrm{q}_{\mathrm{zn}}^{2+}(\mathrm{mg} / \mathrm{g})$} \\
\hline & & & & & \multicolumn{3}{|c|}{ Time (minutes) } \\
\hline & 30 & 60 & 90 & & 30 & 60 & 90 \\
\hline 20.72 & 2.7374 & 2.7453 & 2.7463 & 6.538 & 0.8513 & 0.8543 & 0.8558 \\
\hline 41.44 & 5.4539 & 5.4808 & 5.4843 & 13.076 & 1.6942 & 1.6992 & 1.7022 \\
\hline 62.16 & 8.1724 & 8.1980 & 8.2068 & 19.614 & 2.5206 & 2.5334 & 2.5403 \\
\hline 82.88 & 10.8873 & 10.9198 & 10.9312 & 26.152 & 3.3348 & 3.3696 & 3.3832 \\
\hline 103.6 & 13.6089 & 13.6383 & 13.6430 & 32,69 & 4.1434 & 4.1911 & 4.2119 \\
\hline 124.32 & 16.3244 & 16.3576 & 16.3646 & 39.228 & 4.9440 & 5.0212 & 5.0390 \\
\hline 145.04 & 19.0078 & 19.0697 & 19.0773 & 45.766 & 5.7567 & 5.8275 & 5.8471 \\
\hline 165.76 & 21.7170 & 21.7609 & 21.7641 & 52.304 & 6.5589 & 6.6069 & 6.6270 \\
\hline 186.48 & 24.4041 & 24.4547 & 24.4604 & 58.842 & 7.3489 & 7.4212 & 7.4605 \\
\hline 207.2 & 27.0849 & 27.1693 & 27.1772 & 65.38 & 8.1155 & 8.1953 & 8.2411 \\
\hline
\end{tabular}


However, considering that, at an alkaline $\mathrm{pH}$, the ions studied can precipitate in the form of hydroxides, and the process of adsorption can be thus stopped or attenuated, a $\mathrm{pH}$ of 6 was chosen as the optimum - a value at which lead and zinc exist in the form of divalent ions, and is recommended by the literature. ${ }^{21}$

\section{Contact time}

The contact time between the two phases, necessary to achieve the equilibrium state, is another important parameter of the adsorption process that needs to be optimized. Given the complexity of the lignin structure, the migration of the two metal ions to the internal functional groups may require a variable contact time to achieve the adsorption equilibrium, which is why the adsorption ability of lignin has been tested for three different contact times: 30, 60, 90 minutes.

The increase in the contact time between the two phases of the adsorption system leads to an increase in the amount of metal ions retained on the lignin, in the case of both $\mathrm{Pb}$ (II) ions and $\mathrm{Zn}$ (II) ions. This increase is more pronounced in the initial stage, for both metal ions studied, then the process becomes slower, reaching a maximum after 60 minutes. At this point, saturation is probably reached and thus, the adsorption process respects Le Châtelier's principle of mobile equilibrium. Under these circumstances, the contact time of 60 minutes can be considered as the optimal value, as it is sufficient to achieve equilibrium in the retention of $\mathrm{Pb}$ (II) and $\mathrm{Zn}$ (II) ions from aqueous solutions onto the unmodified Sarkanda grass lignin.

\section{Adsorption isotherms}

By using adsorption isotherms, we can see the two phases of the adsorption system and the distribution profile of the two metal ions studied. Following the graphical representation $\mathrm{q}(\mathrm{mg} / \mathrm{g})$ according to the values of the equilibrium concentration of the metal ions in the aqueous solution (c, $\mathrm{mg} / \mathrm{L})$, the isotherms obtained experimentally for the adsorption of $\mathrm{Pb}$ (II) and $\mathrm{Zn}$ (II) ions onto the lignin are nonlinear in the range of concentration studied, exhibiting a typical behaviour. For their modeling, the classical Freundlich and Langmuir models were used, to obtain an insight into the way the two ions are fixed on the surface of lignin - through mono- or multi-layer adsorption. Subsequently, linear dependencies corresponding to the Freundlich and Langmuir models were obtained, and the values of the characteristic parameters for each model were calculated from the regression equations, together with the values of the correlation coefficients obtained.

The linear representation of the Freundlich model for the adsorption of $\mathrm{Pb}$ (II) and $\mathrm{Zn}$ (II) ions from aqueous solutions onto unmodified Sarkanda grass lignin, under optimal experimental conditions (temperature: $20 \pm 0.5{ }^{\circ} \mathrm{C}$, contact time: $60 \mathrm{~min}, \mathrm{pH}$ 6), is shown in Figure 1 ( $\mathrm{a}$ and $\mathrm{b}$ ). The characteristic parameters of the Freundlich model obtained for the adsorption of $\mathrm{Pb}$ (II) and $\mathrm{Zn}$ (II) ions from aqueous solution onto unmodified lignin at $20{ }^{\circ} \mathrm{C}$ and for different contact times are shown in Table 3.

From the analysis of the experimental data (Table 3), it follows that the values of the correlation coefficients obtained for the Freundlich model, for both metal ions, are around 0.99, which means that there are no significant differences between the correlation factors for the two polluting species. Also, the contact time of 60 minutes seems to be the optimal time of adsorption in the case of both ions. The adsorbent seems to have reached saturation, lowering the concentration gradient and leading to a decrease in the rate of adsorption, which can be explained considering that adsorption is a surface process.

The linear representation of the Langmuir model for the adsorption of $\mathrm{Pb}$ (II) and $\mathrm{Zn}$ (II) in aqueous solutions onto unmodified lignin under optimal experimental conditions is presented in Figure 2 ( $a$ and $b$ ). The characteristic parameters of the adsorption process of $\mathrm{Pb}$ (II) and $\mathrm{Zn}$ (II) ions from aqueous solution on unmodified Sarkanda grass lignin at $20{ }^{\circ} \mathrm{C}$, for different contact times, are shown in Table 4.

In the case of the Langmuir model, the values of the correlation coefficients obtained $R^{2} \in(0.98$ 0.99), but are closer to the upper limit 0.99, similarly to the case of the Freundlich model. Also, $\mathrm{R}^{2}$ has slightly higher values for the adsorption of $\mathrm{Zn}^{2+}$, compared to those for $\mathrm{Pb}^{2+}$. Analyzing the correlation coefficients obtained for both models, it is not possible to determine with certainty whether the adsorption is physical or chemical, which will, most likely, be clarified with the help of kinetic models. 


\section{ELENA UNGUREANU et al.}
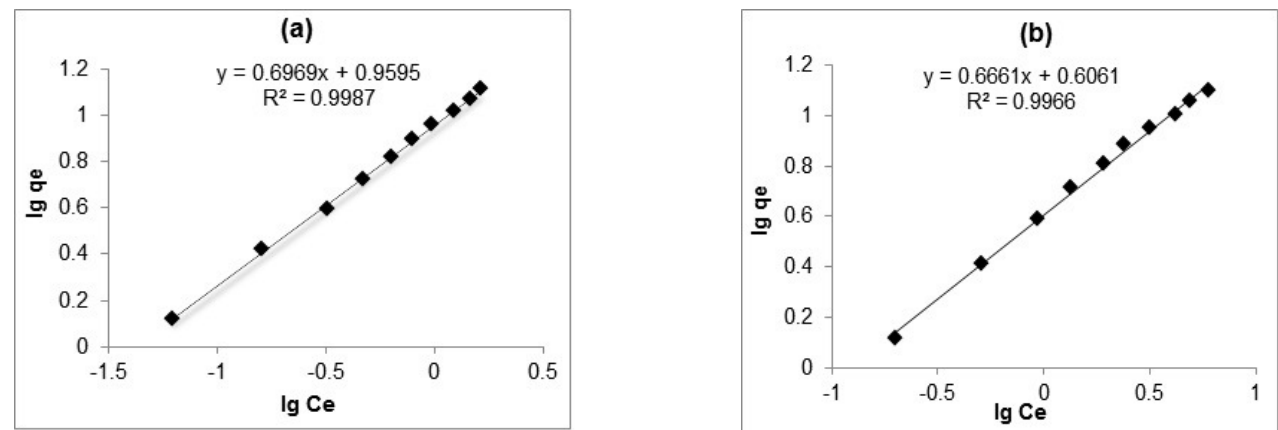

Figure 1: Freundlich model for adsorption of $\mathrm{Pb}$ (II) (a) and $\mathrm{Zn}$ (II) (b) onto unmodified Sarkanda grass lignin for 60 minutes
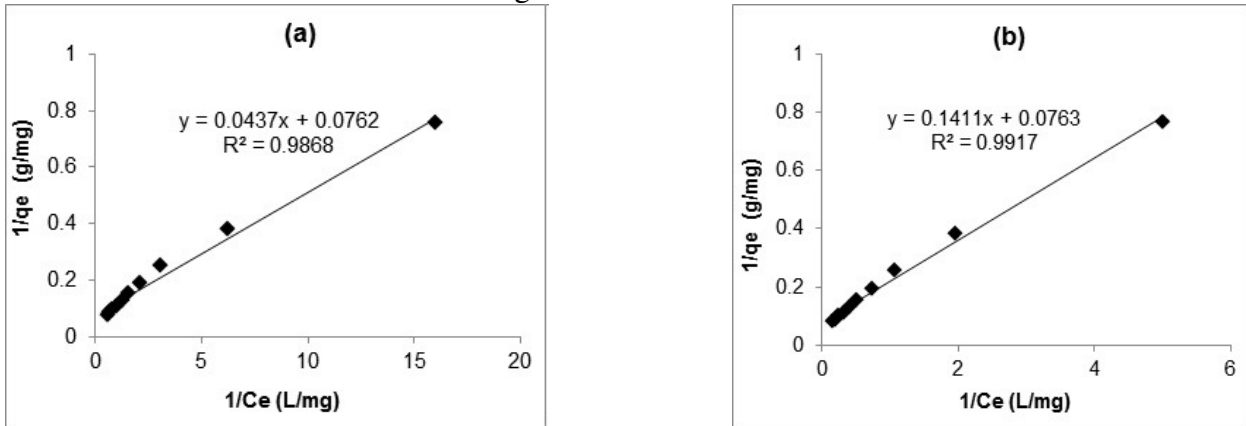

Figure 2: Langmuir model for adsorption of $\mathrm{Pb}(\mathrm{II})$ (a) and $\mathrm{Zn}$ (II) (b) onto unmodified Sarkanda grass lignin for 60 minutes

Table 3

Characteristic parameters of the Freundlich model

\begin{tabular}{lcccc}
\hline Pollutant & Time $(\min )$ & $\mathrm{R}^{2}$ & $1 / \mathrm{n}$ & $\mathrm{k}_{\mathrm{F}}$ \\
\hline \multirow{2}{*}{$\mathrm{Pb}^{2+}$} & 30 & 0.9971 & 0.9028 & 2.1586 \\
& 60 & 0.9987 & 0.9595 & 2.0070 \\
& 90 & 0.9990 & 0.9694 & 1.9776 \\
\hline \multirow{2}{*}{$\mathrm{Zn}^{2+}$} & 30 & 0.9982 & 0.5506 & 1.9286 \\
& 60 & 0.9966 & 0.6061 & 1.9466 \\
& 90 & 0.9952 & 0.6341 & 1.9460 \\
\hline
\end{tabular}

Table 4

Characteristic parameters of the Langmuir model

\begin{tabular}{lcccc}
\hline Pollutant & Time $(\min )$ & $\mathrm{R}^{2}$ & $\mathrm{q}_{\max .}(\mathrm{mg} / \mathrm{g})$ & $\mathrm{K}_{\mathrm{L}}$ \\
\hline \multirow{2}{*}{$\mathrm{Zn}^{2+}$} & 30 & 0.9822 & 13.0208 & 0.0651 \\
& 60 & 0.9868 & 13.1233 & 0.0759 \\
& 90 & 0.9899 & 13.2100 & 0.0754 \\
\hline \multirow{2}{*}{$\mathrm{Pb}^{2+}$} & 30 & 0.9926 & 12.5470 & 0.0786 \\
& 60 & 0.9917 & 13.1061 & 0.0754 \\
& 90 & 0.9910 & 13.1926 & 0.0750 \\
\hline
\end{tabular}

The optimal contact time can be considered that of 60 minutes, as during this contact time, the amount of adsorbed polluting species retained per unit mass of the adsorbent recorded the maximum value.

It also results from the Langmuir model that the surface of lignin can be considered homogeneous, the adsorption of the ions occurring until the formation of a monolayer covering the solid particles. The maximum adsorption capacity $\left(\mathrm{q}_{\max }, \mathrm{mg} / \mathrm{g}\right)$, calculated from the Langmuir model, reached values between $13.02 \mathrm{mg} / \mathrm{g}$ and $13.21 \mathrm{mg} / \mathrm{g}$ for $\mathrm{Pb}(\mathrm{II})$, and between $12.54 \mathrm{mg} / \mathrm{g}$ and $13.19 \mathrm{mg} / \mathrm{g}$ for $\mathrm{Zn}$ (II). 
These values are comparable to those reported for other types of low-cost materials in the literature. ${ }^{13}$ Analyzing the behavior of both ions, it can be inferred that both $\mathrm{Zn}^{2+}$ and $\mathrm{Pb}^{2+}$ show a good ability to bind with lignin, with a "plus" for lead, probably due to more intense complexing interactions.

Thus, it can be concluded that lignin is a good alternative as an adsorbent with potential application in the retention of $\mathrm{Pb}$ (II) and $\mathrm{Zn}$ (II) ions. On the other hand, the high values obtained for the Langmuir $\left(\mathrm{K}_{\mathrm{L}}\right)$ constant, which can be correlated with the energy of binding by adsorption, suggest that strong interactions (ionic exchange or superficial complexation) occur between the metal ions of $\mathrm{Pb}$ (II) and $\mathrm{Zn}$ (II) from the aqueous solution and the functional groups on the surface of the lignin.

\section{Kinetic studies}

The kinetic parameters of the adsorption process of $\mathrm{Zn}$ (II) and $\mathrm{Pb}$ (II) ions onto lignin were determined using the specific kinetic models: the Lagergren model for adsorption in a solid-liquid system and the Ho \& McKay kinetic model to reflect the adsorption capacity of the solid phase. Figures 3 and 4 illustrate the linear dependencies obtained for each kinetic model, for the adsorption of $\mathrm{Pb}(\mathrm{II})$ and $\mathrm{Zn}$ (II) ions from aqueous solutions on Sarkanda grass lignin, under optimal conditions, at the initially normalized concentration of $10 \mathrm{mg} / \mathrm{mL}$. The characteristic kinetic parameters, calculated from the slopes and the orderly intercept of these dependencies, are presented synthetically in Tables 5 and 6.

From the comparison of the kinetic data obtained experimentally and those represented according to the pseudo-first order Lagergren model, it is observed that $\mathrm{Zn}(\mathrm{II})$ ions are retained more intensely than $\mathrm{Pb}$ (II) ions from aqueous solutions on the lignin substrate. For $\mathrm{Zn}^{2+}$ adsorption, the correlation coefficient values belong to the range of 0.72-0.99, while for $\mathrm{Pb}^{2+}$ adsorption, these are within the range of 0.87 0.94, which might suggest that electrostatic interactions probably established between the metal ions and the functional groups of the lignin, which are influenced by the nature of the metal ion. Compared to $\mathrm{Zn}^{2+}$, it seems that $\mathrm{Pb}^{2+}$ participates more actively in the ion exchange interactions that take place on the surface of lignin in the early stages of adsorption.

Given that some correlation coefficient values in the case of the pseudo-first order Lagergren kinetic model are below 0.95, it can be inferred that this kinetic model has limited applicability for the kinetic description of the adsorption of $\mathrm{Pb}^{2+}$ and $\mathrm{Zn}^{2+}$ ions from aqueous solutions on lignin. Therefore, it can be stated that the pseudofirst order kinetic model is less appropriate for describing the adsorption process in the present study, and for this reason, the Ho \& McKay pseudo-second order model was also examined.

The kinetic parameters of the pseudo-second order Ho \& McKay model obtained for the adsorption of $\mathrm{Pb}$ (II) and $\mathrm{Zn}$ (II) ions from aqueous solution onto unmodified Sarkanda grass lignin are presented in Table 6 .

Analyzing the experimental data, it follows that the Ho \& McKay pseudo-second order kinetic model best describes the adsorption of the $\mathrm{Pb}^{2+}$ and $\mathrm{Zn}^{2+}$ metal ions onto lignin.

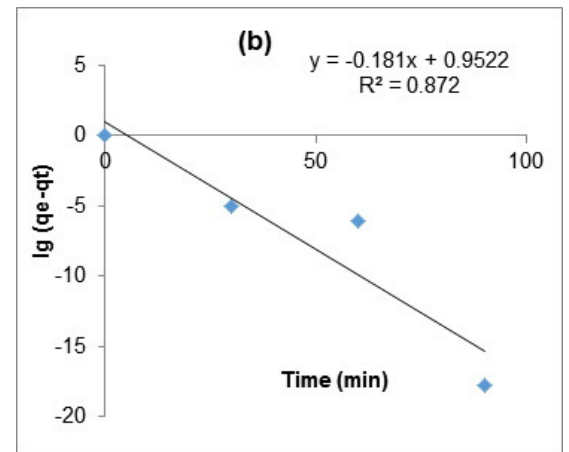

Figure 3: Lagergren model for adsorption of $\mathrm{Pb}(\mathrm{II})$ (a) and $\mathrm{Zn}(\mathrm{II})$ (b) ions onto unmodified Sarkanda grass lignin 


\section{ELENA UNGUREANU et al.}
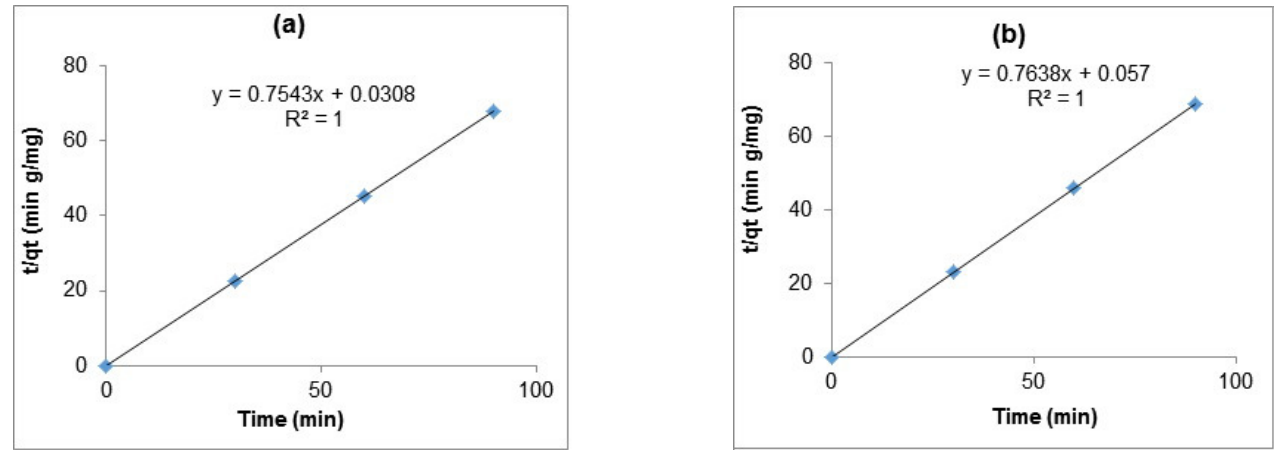

Figure 4: Linear representation of the pseudo-second order Ho \& McKay model for adsorption of $\mathrm{Pb}(\mathrm{II})$ (a) and $\mathrm{Zn}$ (II) (b) ions onto unmodified Sarkanda grass lignin

Table 5

Kinetic parameters of the pseudo-first order Lagergren model for adsorption of $\mathrm{Pb}$ (II) and $\mathrm{Zn}$ (II) ions

\begin{tabular}{ccccc}
\hline Pollutant & $\begin{array}{c}\mathrm{c}_{\mathrm{i}} \\
\mathrm{mg} / \mathrm{mL}\end{array}$ & $\mathrm{R}^{2}$ & $\begin{array}{c}\mathrm{q}_{\mathrm{e}} \\
\mathrm{mg} / \mathrm{g}\end{array}$ & $\begin{array}{c}\mathrm{K}_{1} \\
\mathrm{~min}^{-1}\end{array}$ \\
\hline \multirow{4}{*}{$\mathrm{Pb}^{2+}$} & 10 & 0.9425 & 1.5078 & -0.0019 \\
& 30 & 0.9353 & 1.8166 & -0.0017 \\
& 40 & 0.8893 & 2.2578 & -0.0017 \\
& 50 & 0.8302 & 5.2677 & -0.0021 \\
& 60 & 0.8845 & 3.3091 & -0.0019 \\
& 70 & 0.8598 & 2.3909 & -0.0017 \\
& 80 & 0.9012 & 3.5948 & -0.0020 \\
& 90 & 0.8977 & 3.1336 & -0.0020 \\
& 100 & 0.8769 & 4.3068 & -0.0019 \\
\hline \multirow{4}{*}{$\mathrm{Zn}^{2+}$} & 10 & 0.8720 & 2.5914 & -0.00019 \\
& 20 & 0.8249 & 4.9958 & -0.00013 \\
& 30 & 0.8460 & 3.2245 & -0.00010 \\
& 40 & 0.7668 & 10.7006 & -0.00014 \\
& 50 & 0.7656 & 9.2248 & -0.00012 \\
& 60 & 0.7696 & 11.0066 & -0.00012 \\
& 70 & 0.7395 & 20.6910 & -0.00014 \\
& 80 & 0.7583 & 11.1774 & -0.00013 \\
& 90 & 0.7445 & 9.4763 & -0.00011 \\
& 100 & 0.7246 & 13.7261 & -0.00012 \\
\hline
\end{tabular}

Table 6

Kinetic parameters of the pseudo-second order Ho \& McKay model for adsorption of $\mathrm{Pb}$ (II) and $\mathrm{Zn}(\mathrm{II})$ ions

\begin{tabular}{ccccc}
\hline $\begin{array}{c}\mathrm{c}_{\mathrm{i}} \\
\mathrm{mg} / \mathrm{mL}\end{array}$ & $\begin{array}{c}\mathrm{q}_{\mathrm{e}} \\
\mathrm{mg} / \mathrm{g}\end{array}$ & $\begin{array}{c}\mathrm{K}_{2} \\
\mathrm{~g} / \mathrm{mg} \cdot \mathrm{min}\end{array}$ & $\begin{array}{c}\mathrm{q}_{\mathrm{e}} \\
\mathrm{mg} / \mathrm{g}\end{array}$ & $\begin{array}{c}\mathrm{K}_{2} \\
\mathrm{~g} / \mathrm{mg} \cdot \mathrm{min}\end{array}$ \\
\hline \multicolumn{2}{c}{$\mathrm{Pb}^{2+}$} & \multicolumn{2}{c}{$\mathrm{Zn}^{2+}$} \\
\hline 10 & 1.3257 & 18.473 & 1.3092 & 10.234 \\
30 & 2.6483 & 5.3401 & 2.6041 & 5.7375 \\
40 & 3.9619 & 4.4240 & 3.8865 & 2.3476 \\
50 & 5.2770 & 3.4529 & 5.1760 & 1.1311 \\
60 & 7.89876 & 4.7027 & 6.4474 & 0.6795 \\
70 & 9.2081 & 2.3591 & 7.7160 & 0.5136 \\
80 & 10.504 & 3.4857 & 8.9525 & 0.5354 \\
90 & 11.806 & 2.8696 & 10.141 & 0.6895 \\
100 & 13.123 & 1.7595 & 12.615 & 0.4081 \\
\hline
\end{tabular}


If for the pseudo-first order Lagergren model, $\mathrm{R}^{2}$ had values ranging between 0.72 and 0.99 , in the Ho \& McKay model, $\mathrm{R}^{2}$ is uniform in the case of both ions, which can lead to the hypothesis that, in the adsorption mechanism of of $\mathrm{Pb}$ (II) and $\mathrm{Zn}$ (II) ions from aqueous solutions onto lignin, the rate-determining step is the chemical interaction between the metal ions and the functional groups in the structure of the adsorbent. This probability is supported by the other parameters obtained: $\mathrm{q}_{\mathrm{e}}$ and $\mathrm{K}_{2}$, which show more pronounced adsorption of $\mathrm{Pb}$ (II) than of $\mathrm{Zn}$ (II), which is probably explained by higher affinity between the lead ions and lignin. Also, by correlation with the parameters obtained in the case of the Freundlich and Langmuir models, it can be stated that chemo-sorption is predominant at the expense of physical adsorption, and the active centers on the lignin surface are accessible for the $\mathrm{Pb}(\mathrm{II})$ and $\mathrm{Zn}(\mathrm{II})$ ions from the aqueous solution. Therefore, the experimental data show that the Ho \& McKay pseudo-second order kinetic model is the most appropriate one to describe the adsorption of $\mathrm{Pb}$ (II) and $\mathrm{Zn}$ (II) on lignin, suggesting its chemical nature, probably by the formation of complexes depending on the availability of functional groups of lignin.

From the analysis of the obtained results, it follows that the adsorption of $\mathrm{Pb}$ (II) and $\mathrm{Zn}$ (II) ions from aqueous solutions on unmodified Sarkanda grass lignin probably takes place in two successive stages: in the first stage, adsorption is achieved more rapidly by ion-exchange interactions that occur on the surface of the lignin, followed by a second, much slower stage, where intraparticle diffusion becomes more important in the retention of metal ions on the functional groups in the pores of the lignin. Therefore, it can be concluded that lignin will act as a chemical substrate in which the functional groups are strongly related to the skeleton and can retain the polluting species from the solution through specific chemical interactions. This recommends lignin as an economically viable alternative for wastewater treatment, especially in Romania, where significant quantities of residual lignin result as a waste from biomass processing by biorefining.

\section{CONCLUSION}

In the present study, unmodified Sarkanda grass lignin has been demonstrated as an effective adsorbent under precisely established/optimal experimental conditions - room temperature (20 \pm $0.5^{\circ} \mathrm{C}$ ), low acid to neutral $\mathrm{pH}$ for both lignin and aqueous solutions of zinc and lead ions ( $\mathrm{pH}$ 6), a dose of $5 \mathrm{~g}$ adsorbent/L pollutant solution, in the concentration range studied (Table 2), during a contact time of 60 minutes.

Isothermal modeling of experimentally obtained adsorption data was done using the Freundlich and Langmuir models. From the analysis of the correlation coefficients for both models, it was not possible to determine with certainty whether the adsorption was physical or chemical, but it was further clarified with the help of kinetic models.

From a kinetic point of view, the adsorption of $\mathrm{Zn}$ (II) and $\mathrm{Pb}$ (II) ions from aqueous solutions onto unmodified Sarkanda grass lignin was best described by the Ho \& McKay pseudo-second order kinetic model, which considers that the ratedetermining step of the adsorption process involves the chemical interaction between zinc and lead ions as polluting species in aqueous solutions and the functional groups of Sarkanda grass lignin.

Therefore, it can be concluded that Sarkanda grass lignin used as an adsorbent can be an efficient and economically viable solution for water pollution control, especially in countries, where this waste is found in significant quantities.

ACKNOWLEDGEMENT: The authors declare no specific funding for this work.

\section{REFERENCES}

1 M. C. Cann, "Sustainability of Biomass through Bio-based Chemistry”, CRC Press, 2021, https://www.routledge.com/

2 S. E. Bailey, T. J. Olin, M. R. Bricka and D. D. Adrian, Water Res., 33, 2469 (1999), https://doi.org/10.1016/S0043-1354(98)00475-8

3 E. Ungureanu, "Lignin, Aromatic Natural Polymer with High Potential for Recovery", Pim Press, Iasi, 2011, http://www.pimcopy.ro/editura/

4 M. E. Fortună, V. Vasilache, M. Ignat, M. Silion, T. Vicol et al., PloS One, 13, e0202441 (2018), https://doi.org/10.1371/journal.pone.020244

5 F. Le Digabel and A. L. Avérous, Carbohyd. Polym., $\quad 66, \quad 537 \quad$ (2006), https://doi.org/10.1016/j.carbpol.2006.04.023

6 S. P. Suhas, J. Carrot and R. Carrot, Bioresour. Technol., 98, $2301 \quad$ (2007), https://doi.org/10.1016/j.biortech.2006.08.008

7 A. Demirbas, J. Hazard. Mater., 157, 220 (2008), https://doi.org/10.1016/j.jhazmat.2008.01.024

8 R. H. Crist, J. R. Martin and D. R. Crist, Sep. Sci. Technol., 39, 1535 (2004), https://doi.org/10.1081/SS120030781 


\section{ELENA UNGUREANU et al.}

9 D. Mohan, C. U. Pittman Jr. and P. H. Steele, J. Colloid Interface Sci., 297, 489 (2006), https://doi.org/ 10.1016/j.jcis.2005.11.023

10 X. Y. Guo, A. Z. Zhang and X. Q. Shan, J. Hazard. Mater., $\quad 151, \quad 134 \quad$ (2008), https://doi.org/10.1016/j.jhazmat.2007.05.065

11 A. Lobiuc, S. Olaru, E. I. Hancu, N. Costica, M. E. Fortuna et al., Rev. Chim., 69, 1628 (2018), https://doi.org/10.37358/RC.18.7.6384

12 M. Jaishankar, T. Tseten, N. Anbalagan, B. B. Mathew and K. N. Beeregowda, Interdiscip. Toxicol., 7, 60 (2014), https://doi.org/10.2478/intox-2014-0009

13 G. Rusu, Ph.D. Thesis, "Gh. Asachi”" Polytechnic University of Iasi, Romania, 2015

14 M. Rahmati, M. M. Rabbani, P. Abdolali and A. Keshtkar, J. Hazard. Mater., 185, 401 (2011), https://doi.org/10.1016/j.jhazmat.2010.09.047

15 P. A. Marques, M. F. Rosa and H. M. Pinheiro, Bioprocess Eng., 23, $135 \quad$ (2000), https://doi.org/10.1007/PL00009118

16 K. H. Chong and B. Volesky, Biotechnol. Bioeng., 47, 451 (1995), https://doi.org/10.1002/bit.260470406

17 Y. S. Ho, C. T. Huang and H. W. Huang, Process. Biochem., $\quad 37, \quad 1421 \quad$ (2002), https://doi.org/10.1016/S0032-9592(02)00036-5

18 V. I. Popa, E. Ungureanu and T. Todorciuc, Cellulose Chem. Technol., 41, 123 (2007), https://www.cellulosechemtechnol.ro

19 T. Todorciuc, L. Bulgariu and V. I. Popa, Cellulose Chem. Technol., 49, $439 \quad$ (2015), https://www.cellulosechemtechnol.ro/pdf/CCT56(2015)/p.439-447.pdf

20 P. Senthil Kumar, C. Vincent, K. Kirthika and K. Sathish Kumar, J. Chem. Eng., 27, 339 (2010), https://doi.org/10.1590/S0104-66322010000200012

21 A. H. Chen, S. C. Liu and C. Y. Chen, J. Hazard.

Mater.,

154,

184

(2008),

https://doi.org/10.1016/j.jhazmat.2007.10.009 